\title{
Sebastião em O primo Basílio: um caso exemplar de personagem secundária?
}

\author{
Sebastião in O primo Basílio ("Cousin Bazilio"): an exemplary case of character?
}

\author{
José Luís Giovanoni Fornos \\ Universidade Federal do Rio Grande - Rio Grande do Sul - Brasil
}

\begin{abstract}
Resumo: O presente ensaio examina o conceito de personagem, interrogando acerca da sua importância na economia do texto narrativo. Ressalta sua estrutura à luz das concepções semiológicas de acordo com Philippe Hamon, bem como o papel do inconsciente na constituição do sujeito e sua relação com a dinâmica social. Igualmente observa o valor da recepção a partir de Wolfgang Iser e Umberto Eco. Para tais reflexões, se utiliza da personagem Sebastião, presente no romance O primo Basílio, de Eça de Queirós, enquadrando-a como figura de recalque do desejo amoroso, curvando-se aos preceitos morais da sociedade portuguesa oitocentista.
\end{abstract}

Palavras-chave: Personagem; Recepção; Romance; Eça de Queirós

\begin{abstract}
This essay is aimed at examining the concept of character by questioning its importance in the economy of narrative text. The structure of a character is emphasized in the light of semiological assumptions according to Philippe Hamon, as well as the role of the unconscious in the constitution of the subject and its relation with the social dynamics are discussed. Also the value of the reception is noted drawing on Wolfgang Iser e Umberto Eco. For such reflections, the character Sebastião is used, from the novel O primo Basílio ("Cousin Bazilio"), by Eça de Queirós, framing him as a figure of repression of the amorous desire, subject to the moral precepts of the nineteenth-century Portuguese society.
\end{abstract}

Keywords: Character; Reception; Novel; Eça de Queirós

A manifestação de Machado de Assis favorável às qualidades artísticas promissoras de Eça de Queirós, não impediu que o escritor brasileiro traçasse algumas advertências quanto à estruturação do segundo romance do autor português: O primo Basílio (1878). Entre as observações feitas, o escritor brasileiro chamava a atenção, em sua crítica, para a fragilidade do livro na composição das personagens, em particular, a figura de Luísa, caracterizando-a sem força moral, reduzindo-a a um "títere". Em Luísa, afirma Machado, não havia "nenhuma razão moral, nenhuma paixão, sublime ou subalterna, nenhum amor, nenhum despeito, nenhuma perversão sequer" que justificasse sua queda. Para autor, "Luísa resvala no lodo, sem vontade, sem repulsa, sem consciência". ${ }^{1}$ No seu entendimento, para que Luísa atraísse a atenção, era necessário que as tribulações que

\footnotetext{
${ }^{1}$ As citações pertencem à crítica intitulada $O$ primo Basílio e consta no livro Machado de Assis, Joaquim Maria. Obras completas de Machado de Assis: Esaú e Jacó; críticas literárias; críticas teatrais. São Paulo: Formar, s/d., p. 165.
}

a afligiam viessem dela mesma; fosse "uma rebelde ou uma arrependida"; tivesse "remorsos ou imprecações" (ASSIS, s/d., p. 165).

Ao comentar o problema de concepção que envolvia a construção da heroína de $O$ primo Basílio, Machado de Assis passava a discutir, na verdade, outra questão significativa acerca da produção artística de um escritor: o vínculo a um determinado programa estético-literário. $\mathrm{O}$ escritor brasileiro alertava Eça quanto aos possíveis prejuízos estéticos à elaboração do texto literário quando da filiação irrestrita a um movimento literário. Machado reivindicava do autor português um distanciamento crítico diante das prerrogativas impostas por um programa teórico-literário e apontava que, com tais preocupações de escola, em O Primo Basílio:

Não admira que a pena do autor chegue ao extremo de correr o reposteiro conjugal; que nos talhe as suas mulheres pelos aspectos e trejeitos da concupiscência; que escreva reminiscências e alusões de um erotismo, que Proudhon chamaria oni-sexual e onímodo; que 
no meio das tribulações que assaltam a heroína, não lhe infunda no coração, em relação ao esposo, as esperanças de um sentimento superior, mas somente os cálculos da sensualidade e os 'ímpetos da concubina'; que nos dê as cenas repugnantes do paraíso (ASSIS, s/d., p. 165).

$\mathrm{O}$ ataque realizado por Machado à adesão a uma escola literária, - nesse caso ao Realismo-Naturalismo -, evidencia a desconfiança do escritor a um tipo de literatura cujo fim destinava-se a uma ação político-reformadora da sociedade. A questão que se fundamenta em discussões acerca da função do texto literário, encontra as seguintes palavras de Eduardo Prado Coelho ao comentar a polêmica entre "realistas" e "vanguardistas":

O realista, encara a literatura como um meio que afinal acaba por se tornar um fim ( na medida em que transige com a estrutura da obra concreta), o outro encara a literatura como um fim que afinal acaba por tornar um meio ( na medida em que as inovações ou revoluções da escrita implicam ou pedem as do mundo e da vida) (COELHO, 1972, p. 118).

Eça de Queirós, consciente da questão, estava convencido de que era possível realizar um projeto artístico, sem diminuição de suas qualidades estéticas que, em última instância, produzisse críticas à sociedade burguesa, em especial, à portuguesa e suas instituições, com finalidades reformadoras. O escritor português, ainda que próximo a uma escola literária e dos fundamentos ideológicos que a sustentava, escapa de seus mecanismos empobrecedores, escarnecendo aqueles que o procuravam reduzi-lo apenas a um epígono sem imaginação:

Ora meu nome tem sido geralmente, em Portugal e no Brasil, associado a este realismo e a nova instituição, porque ignoro se é uma nova arte, uma nova política, uma nova religião ou uma nova filosofia; não sei mesmo se não será um novo clube ou uma companhia de seguros! (QUEIRÓS, 1965, p. 174).

Caso se desconsidere a defesa realizada por Eça, prevalecendo seu comprometimento às teses veiculadas pela escola realista-naturalista, importa saber, ao leitor de hoje, até que ponto tal engajamento compromete as qualidades artísticas de sua obra. Particularmente, trata-se de observar nas personagens queiroseanas qualidades que vão além do retrato crítico de uma determinada época. Dessa forma, cabe saber se, tendo em vista a escolha de um modelo teórico-estético, cuja execução visava, sobretudo, a "uma vasta ação moralizadora no seio da sociedade" (REIS, 1975, p. 141), a obra do escritor mantém, para o leitor de hoje, dispositivos que lhe assegurem a sua importância na história da literatura. Desde já, pode-se afirmar que o texto queiroseano se mantém como espaço renovador ao escolher a denúncia, realizada com ironia, aos costumes de uma sociedade que parece ainda estar representada hoje, através de figuras exemplares de seus romances.

Nesse sentido, a importância do leitor na atualização do texto queiroseano ganha destaque. Assim, desde as incursões da estética da recepção, na década de 60, há uma busca de um equilíbrio entre a obra, sua análise e a colaboração do leitor na investigação. O leitor ajustado como integrante do processo de construção e tematização da narrativa ficcional assume papel significativo a partir de distintas formulações teóricas. Destacam-se, entre elas, os trabalhos de Hans Robert Jauss que enfatizam a importância da recepção como categoria de análise na história da literatura, questionando sua ausência nas hermenêuticas marxista e estruturalista. De acordo com Cruz (2016),

ao valorizar o caráter dialógico do texto literário, superior à suposta imanência da obra, como propunham os formalistas, Jauss sugere uma história da literatura orientada a partir da leitura historicamente contextualizada das obras, como processo continuamente renovado, na medida em que se alteram os horizontes de expectativa de quem lê. A ideia de um "horizonte de expectativas" é uma das bases da teoria de Jauss e corresponde àquilo que é visível e pode ser alterado, de acordo com as concepções do leitor. O leitor reage à obra segundo seu horizonte de expectativas, resultado de um conjunto de conhecimentos socialmente construídos em sintonia com as demandas de seu contexto histórico. O potencial artístico estaria, então, ligado à capacidade de uma obra em atender horizontes de expectativas distintos, permitindo vários níveis e tipos de leitura, em diferentes épocas. Enquanto para Jauss interessam as circunstâncias histórico-sociológicas em que as obras são lidas (CRUZ, 2016, p. 55).

Numa perspectiva ontológica da obra de arte literária, destaca-se a "teoria do efeito estético" formulada por Wolfgang Iser. De acordo com o autor, "se o texto ficcional existe graças ao efeito que estimula nas nossas leituras, então deveríamos compreender a significação mais como produto de efeitos experimentados, ou seja, de efeitos atualizados do que como uma ideia que antecede a obra e se manifesta nela" (ISER, 1996, p. 54).

Embora a "estética da recepção" e a "teoria do efeito estético" estejam interligadas, a primeira deriva de uma história dos juízos de leitores reais, enquanto a segunda funda-se no texto. Para Iser, a teoria da recepção "diz respeito ao modo como os textos têm sido lidos e assimilados nos vários contextos históricos, procurando mapear as atitudes que determinaram certo modo de compreensão numa situação específica" (ISER, 1999, p. 19). 
Nas palavras de Iser (1996), "a interpretação ganha uma nova função: em vez de decifrar o sentido, ela evidencia o potencial de sentido proporcionado pelo texto" (ISER, 1996, p. 54). Segundo o autor, "a interpretação que buscava na obra sua significação queria instruir o leitor a respeito da significação que ele deveria reconhecer no texto" (ISER, 1996, p. 54).

O deslocamento do primado do texto, composto por seu código-mestre, para a uma maior presença e valorização do leitor, fez com que muitas interpretações trouxessem o retorno de textos mergulhados no esquecimento.

Segundo Eco, a interpretação envolve uma dialética entre a estratégia textual e a reposta do leitor-modelo. Este pressupõe um conjunto de operações estabelecidas que deva ser realizadas para que o texto seja atualizado no seu contexto potencial. Na cooperação entre as instâncias do emissor e receptor se instala a estratégia textual que supõe as intenções virtualmente contidas nos enunciados que permitem ao receptor recuperar, com a máxima aproximação possível, o código do emissor, supondo sempre a solução do que ocorre com a personagem, com a trama e com o próprio receptor na hipótese de se concretizar uma performance ingênua ou sagaz.

Em Lector in fabula (1979), Eco promove o conceito de "leitor-modelo", entidade tão textual quanto o autor, que segue os protocolos de leitura propostos pelo emissor, como pistas, preenchendo os espaços vazios. Isso significa que o texto está à espera de uma determinada leitura, que a estrutura textual oferece indícios para a recepção. Eco afirma que

o texto está, portanto, entretecido de espaços em branco, de interstícios a encher, e quem o emitiu previa que eles fossem preenchidos e deixou-os em branco por duas razões. Antes de mais, porque o texto é um mecanismo preguiçoso (ou econômico), que vive da mais-valia de sentido que o destinatário lhe introduz. Em segundo lugar, porque, à medida que passa, a pouco e pouco, da função didascálica à função estética, um texto pretende deixar ao leitor a iniciativa interpretativa. Um texto quer que alguém o ajude a funcionar (ECO, 1979, p. 55).

Tomando o texto como um mecanismo preguiçoso, ele é emitido para ser continuamente atualizado pelo leitor, a cada leitura, de acordo com sua competência, que nem sempre é adequa a do emissor. O que assegura a cooperação textual entre ambos, diante da possibilidade de interpretações "aberrantes" seria prever um leitor-modelo, capaz de atender às restrições interpretativas impostas pelo texto (idioma, linguagem, temática, forma, etc.).

Dessa forma, na mesma medida em que as interpretações são infinitas, o papel do discurso emitido deve ser o de limitá-las, através do mapeamento do leitormodelo. E, assim como o autor empírico formula uma hipótese de leitor-modelo, o leitor real também cria o seu "autor", a partir de estratégias textuais.

Todavia, de acordo com Eco, alguns conceitos são reproduzidos sem o devido cuidado e aquele papel limitado do leitor como construtor de sentidos em um texto passa a ser visto como incondicional. Em Interpretação e superinterpretação, observa: "A leitura aberta que eu defendia era uma atividade provocada por uma obra. Tenho a impressão de que, no decorrer das últimas décadas, os direitos dos intérpretes foram exagerados" (ECO, 1993, p. 27). Nem todas as leituras são, portanto, legitimadas, já que o texto impõe limites que devem ser respeitados.

Por outro lado, a dificuldade de se estabelecer parâmetros concretos de leitura projeta interpretações que se distanciam, em extremo, do texto de origem. Diante da situação, pode-se afirmar que tanto o texto quanto o contexto do leitor animam-se mutuamente, revelando, cada um ao seu modo, estratégias de leitura. Nesse sentido, a imparcialidade, requisitada por certo formalismo, ao se impor ao impressionismo do século XIX, bem como um desvio às exclusivas potencialidades do leitor, merecem ressalvas. Jonathan Culler (1997), ao discutir a liberdade e a restrição no processo de leitura, afirma que "sempre hão de haver dualismos: um intérprete e qualquer coisa para interpretar" (CULLER, 1997, p. 32).

Atentos às formulações anteriores, deter-se-á em $O$ primo Basílio na análise da personagem. A escolha dessa categoria se deve à sua importância na composição do texto narrativo, revelando-se "o eixo em torno do qual gira a ação e em função do qual se organiza a economia da narrativa." (REIS, 1988, p. 215) De acordo com Philippe Hamon, "o problema das modalidades de sua análise e seu estatuto constitui um dos pontos de 'fixação' tradicional da crítica (antiga e nova) e de toda teoria da literatura" (HAMON, 1976, p. 69). Segundo Carlos Reis, para Hamon,

manifestada sob a espécie de um conjunto descontínuo de marcas, a personagem é uma unidade difusa de significação, construída progressivamente pela narrativa. Uma personagem é, pois, o suporte das redundâncias e das transformações semânticas da narrativa, é constituído pela soma das informações facultadas sobre o que ela é e sobre o que ela faz. (REIS, 1988, p. 216)

$\mathrm{O}$ entendimento da personagem como signo linguístico implica destacar "sua condição de unidade discreta, suscetível de delimitação no plano sintagmático e de integração numa rede de relações paradigmáticas" (REIS, 1988, p.217). Todavia, é fundamental acentuar 
que o estudo da personagem é tributário das imposições ideológicas e dos filtros culturais de uma época. Tais imposições poderão se tornar condicionantes à leitura da personagem, valorizando-a numa ou outra direção. Para Hamon, daí resulta "as distorções muito frequentes nas leituras", acentuadas nos dias de hoje pela "extensão e heterogeneidade do público" (HAMON, 1976, p. 75). Segundo o teórico francês, é necessário evitar análises em que as condições são fornecidas, com exclusividade, pelo contexto em que se encontra o leitor. Daí o significado do registro de certas características constantes que determinam estatuto específico da personagem. Essa preocupação, ainda que positiva, pode limitar o espaço criativo da leitura, ao desrespeitar a pluralidade de códigos culturais dos leitores.

Em O Primo Basílio, as condicionantes ideológicas do Naturalismo, levadas a cabo pelo narrador, processam um julgamento impiedoso das personagens. $\mathrm{O}$ intenso controle exercido pela voz narrativa sobre a construção da personagem no romance naturalista, definindo-a, por inteiro, o perfil ideológico, contraria ao que Bakhtin detectou como a característica que melhor traduz a permanência do romance enquanto gênero, servindo de critério para sua valorização estética: a polifonia. Para o autor russo, o predomínio do ponto de vista monológico ${ }^{2}$ é ingênuo, visto que a palavra do autor-narrador "penetra em toda parte, em todos os cantos do mundo e da alma subordinando tudo à sua unidade" (BAKHTIN, 1997, p. 56), assim destituindo a genuína palavra da personagem. A palavra do narrador-autor torna a personagem, segundo Bakhtin,

fechada e seus limites racionais são rigorosamente delineados: ela age, sofre, pensa e é consciente nos limites daquilo que ela é, isto é, nos limites de sua imagem definida como realidade; ela não pode deixar de ser o que ela mesma é, vale dizer, ultrapassar os limites do seu caráter, de sua tipicidade, do seu temperamento, sem com isso perturbar o plano monológico do autor para ela (BAKHTIN, 1997, p. 51).

Entretanto, a posição adotada pelo teórico não impossibilita que se analisem variáveis em $O$ primo Basílio, que viabilizem a compreensão das personagens para além daquela fornecida pelo narrador; visto que o mesmo, ainda que possua consciência de suas intenções críticas, não tem domínio permanente de suas investidas. Nesse caso, auxilia as noções de inconsciente e as de

\footnotetext{
2 O recurso da mise en abyme, forma de reduplicação semântica, que funciona como uma espécie de modelo reduzido da obra inteira, e onde as personagens reproduzirão em escala reduzida o sistema global das personagens da obra no seu conjunto, pode indicar em $O$ primo Basílio um desafio à sua estrutura monológica. Com certeza, tal recurso possuía suas limitações, caso seja comparado à auto-reflexividade e à intertextualidade intensa e declarada de muitas narrativas atuais.
}

desejo enquanto categorias importantes para elucidação do comportamento das personagens. $\mathrm{O}$ inconsciente é a zona em que se encontram todas as representações recalcadas fora da consciência, porém continuam a ter vida própria e estão na origem de muitas doenças. Com relação ao desejo, constitui-se, segundo Mezan (1990), "a mola mestra da construção freudiana" (MEZAN, 1990, p.329). De acordo com o autor, na ótica psicanalista freudiana, o desejo

é um movimento psíquico que não visa um objeto exterior - este é visado pela necessidade e depois pela pulsão - mas sim algo que está no interior da psique: a lembrança da percepção que acompanhou a satisfação da necessidade. (...) o desejo depende (...) de uma associação que precede e condiciona sua existência, que lhe mostra um caminho, e que é uma associação de traços e imagens (...) visa por isso reproduzir um estado de satisfação que é sempre anterior, e aquele que surge na cena da realidade só cumpre essa condição (de objeto do desejo) se corresponder de algum modo à imagem da lembrança cuja reprodução é procurada (MEZAN, 1990, p. 357).

A recorrência à psicanálise como chave de leitura serve para a interpretação das personagens, caso se tome suas manifestações como vestígios de desejos encobertos. Ainda que construídas como tipos sociais, ${ }^{3}$ as personagens podem informar aspectos que derivam de paixões, impulsos e desejos recalcados.

As posições acima alteram substancialmente as noções de sujeito, e mais: transformam as pretensões do indivíduo de saber-se a si mesmo enquanto consciência, já que esta podia ser falsa e encobrir as projeções do inconsciente. Ainda que alguns tenham questionado e negado a noção de inconsciente ${ }^{4}$, o seu advento enquanto o outro da consciência atua como uma categoria singnificativa na compreensão da psique humana.

Dessa forma, buscar o sentido das relações estabelecidas entre as personagens para além do enunciado dado, implica aceitar que as escolhas discursivas feitas por essas potencializam outros sentidos. As manifestações expressas pelas personagens deverão ser encaradas como produtos de efeitos experimentados pelo leitor. Tais efeitos aparecem como ideias que antecedem a obra e se manifestam nela.

\footnotetext{
Segundo Carlos Reis, pode considerar o tipo como uma "subcategoria da personagem"; também deve ser entendido "como personagemsíntese entre o individual e o coletivo, entre o concreto e o abstrato, tendo em vista o intuito de ilustrar de uma forma representativa certas dominantes (profissionais, psicológicas, culturais, econômicas, etc.) do universo diegético em que se desenrola a ação, em conexão estreita com o mundo real com que estabelece uma relação de índole mimética. p. 223 (in: Dicionário de teoria da narrativa)

4 A mais célebre dessas críticas é a que expõe J.P. Sartre em $O$ ser e o nada (1943). Segundo o filósofo, o que Freud e os psicanalistas reconhecem como inconsciente deve ser imputado à "má fé".
} 
Dando seguimento às proposições lançadas, a análise centrar-se-á na figura de Sebastião. Os motivos derivam, em primeiro lugar, de torná-la isenta de juízos críticos negativos; em segundo, em virtude de uma série de atitudes que contradizem a descrição "positiva" realizada.

Em O primo Basílio, ${ }^{5}$ a presença de Sebastião deve ser estudada enquanto personagem secundária. A definição ocorre devido à sua "funcionalidade", "peso" e relevância específica no jogo narrativo. Além desses aspectos, há outros que a colocam nessa posição: sua "intervenção na ação", "densidade psicológica" e importância no "espaço social". Ainda que tal fato esteja claramente definido, Sebastião revela-se uma figura promissora. Sua exclusão do quadro competitivo que se instala no romance, impõelhe qualidades positivas, expostas pelo narrador. Contudo, subjaz ao seu comportamento idealmente valorizado, a revelação de atitudes, aparentemente incompreensíveis. Com relação à sua descrição, o narrador declara:

O seu rosto, em plena luz, tinha uma expressão honesta, simples, aberta: os olhos pequenos, azuis de um azul-claro, de uma suavidade séria, adoçavam-se muito quando sorria; e os seus beiços escarlates, sem películas secas, os dentes luzídios, revelavam uma vida saudável e hábitos castos (1998, p.42).

O narrador já enaltecera, em outro momento, as qualidades do amigo "inseparável de Jorge", quando de sua chegada em casa de Luísa, num dos corriqueiros serões: "Ó Sebastião! Ó Sr. Sebastião, Ó Sebastiarrão! Era ele, Sebastião, o grande Sebastião, o Sebastiarrão, Sebastião tronco de árvore - o íntimo, o camarada de Jorge desde o latim, na aula de frei Libório...” (1998, p. 41) Além das qualidades ressaltadas, aparecem palavras em grifo, denunciando, desde já, situações que assinalarão a permanente presença da personagem junto à família Brito de Carvalho. Tal presença decorre de uma longa amizade com o marido de Luísa, desde os tempos de infância, em que os dois compartilhavam os estudos e as recreações, estendendo-se aos tempos de juventude.

A aproximação íntima entre Jorge e Sebastião rompe-se quando Jorge - depois da morte da mãe sentindo-se só, decide-se casar com Luísa, apaixonandose "pelos seus cabelos loiros, pela sua maneira de andar, pelos seus olhos castanhos muito grandes". (1998, p. 17) O "bom" Sebastião, em seu íntimo, deplorou o casamento, revelando, com gravidade, a escolha precipitada e imatura do amigo: "- Casou no ar! Casou um bocado no ar!” (1998, p. 17) Aqui a personagem, dotada de um temperamento cauteloso e de uma inteligência que se mantêm encoberta pela timidez, prevê os acontecimentos

\footnotetext{
QUEIRÓS, Eça. O primo Basílio. São Paulo: Ática, 1998. Todas as citações subsequentes procedem dessa edição; portanto, serão indicadas somente as respectivas páginas.
}

que envolverão o casal. Por outro lado, a fala de Sebastião expõe certa decepção e amargura aos anos que ambos estiveram ligados. $\mathrm{O}$ narrador denuncia o sentimento da personagem:

Já então os dois rapazes vizinhos, Jorge e Sebastião, eram íntimos. Jorge mais vivo, mais inventivo, dominava-o. No quintal, a brincar, Sebastião era sempre o cavalo nas imitações da diligência, o vencido nas guerras. Era Sebastião que carregava os pesos, que oferecia o dorso para Jorge trepar; nas merendas comia todo pão, deixava a Jorge a fruta. Cresceram. E aquela amizade sempre igual, sem amuos, tornou-se na vida de ambos um interesse essencial e permanente.

Todo aquele plano jovial da Sociedade Sebastião $e$ Jorge - chamavam-lhe assim, rindo - desabou, como um castelo de cartas. Sebastião teve um grande pesar (1998, p. 92).

O comportamento íntimo dos dois amigos contribuíra para decepção de Sebastião. ${ }^{6}$ Contudo, o "grande pesar" da personagem está inscrito numa outra ordem, denunciada pelo narrador, por uma "sensualidade" infantil presente na relação. "Sensualidade" esta que havia preocupado Machado de Assis ao tratar do problema da construção que afetava a personagem Luísa. O termo sensualidade, eufemisticamante aplicado por Machado ao comportamento da personagem feminina, deriva-se, na verdade, de outro, tomado como exemplo para a caracterização do comportamento humano no Naturalismo: a sexualidade. No trecho acima, é dessa que se está a comentar. O comportamento de Sebastião em relação a Jorge aproxima-se de uma relação homo afetiva. O comportamento homossexual está presente igualmente entre as mulheres. Numa das passagens, Leopoldina faz revelações à Luísa:

Puseram-se a falar dos "sentimentos". Leopoldina tivera quatro; a mais bonita era Joaninha, a Freitas. Que olhos! E que bem feita! Tinha-lhe feito a corte um mês!...

- Tolices! - disse Luísa corando um pouco.

- Tolices! - Por quê?

Ai!, era sempre com saudades que falava dos "sentimentos". Tinham sido as primeiras sensações, as mais intensas. Que agonia de ciúmes! Que delírio de reconciliações! E os beijos furtados! E os olhares! E os bilhetinhos, e todas as palpitações do coração, as primeiras da vida!

- Nunca - exclamou -, nunca, depois de mulher, senti por um homem o que senti pela Joaninha!... Pois podes crer (1998, p. 124).

\footnotetext{
6 O nome de Sebastião, além do mito que representa no imaginário cultural português, remete à personagem principal do romance naturalista $O$ Barão de Lavos (1891), de Abel Botelho, livro publicado alguns anos depois e que tem como tema a androginia da personagem principal: Sebastião.
} 
A opção feita por Eça, através do narrador, em não explicitar as marcas de uma possível homossexualidade em Sebastião - comparadas às acima citadas - pode revelar diversas questões. Importa aqui, no entanto, é o seguimento dado à personagem após o período em que esteve ligado a Jorge. A frustração vivida por Sebastião encaminhou-o para o amadurecimento $^{7}$ dos seus sentimentos, fazendo com que ele passasse a experimentar uma nova sensação. A nova dimensão de seus sentimentos ocorre a partir da presença de Luísa. Segundo Saraiva e Lopes (s/d), Sebastião "ama assolapadamente Luísa, que cedo sente que ele é o seu mais seguro amparo" (SARAIVA e LOPES, s/d, 910). O amor leva o Sebastião a "assassinar" a empregada Juliana. Antes de tal iniciativa ousada, Sebastião já demonstrara seu interesse, em mínimos gestos, pela esposa de seu melhor amigo. Entretanto, em instante algum, Sebastião concretiza seu amor. Entre as razões, pode-se afirmar que Sebastião possui uma resignação quase religiosa e um senso moral elevado que o leva a um controle de seus desejos, respeitando a confiança de Jorge.

De outro modo, a obsessão de seu amor não satisfeito e sublimado pelo contínuo e excessivo empenho no auxílio à Luísa, salvaguardando-a em muitas situações dos boatos promovidos pela vizinhança, revela o caráter doentio da personagem. A bondade e a timidez, traços exemplares de Sebastião, escondem uma faceta perversa, já que tais características se voltam contra o próprio indivíduo, revelando sua incapacidade de realizar seus desejos.

Sebastião mostra toda sua perversidade reprimida nos momentos em que age, em busca da concretização dos seus anseios. A presença do policial em casa de Luísa e a carta de Jorge entregue à esposa por "engano" são dois momentos máximos que revelam o desmascaramento da fantasia positiva criada pelo narrador na constituição da personagem Sebastião. Nos dois momentos, nota-se a paixão encoberta pela personagem central. Em especial, quando da entrega da carta, age a fim de que possam surgir futuras discórdias entre o casal Luísa e Jorge. A ação não parece ter escrúpulos, demonstrando um caráter suspeito:

- É verdade - dizia Sebastião, revolvendo o maço de papéis.

- Recebi duas; fala em voltar; diz que está muito secado... - E estendendo uma carta a Luísa:

- Pode ver.

Luísa desdobrara-a, e começava a ler; mas Sebastião, estendendo a carta precipitadamente:

- Perdão, não é essa! (1998, p. 202).

\footnotetext{
Na verdade, há um recalcamento dos "sentimentos" anteriores, justificado pelo comportamento tímido da personagem e pela presença de uma nova figura: Luísa, mulher de seu melhor amigo.
}

As atitudes de Sebastião só não se equiparam às de Basílio, pois sua figura recebe, com antecedência, características que são valorizadas naquele meio social. Seu respeito excessivo à Luísa e a solução dada às chantagens de Juliana, num outro contexto, revelariam um caráter débil e perigoso. Sebastião, na tentativa de seduzir a jovem esposa, desconhece qualquer dificuldade, para ajudá-la: “Tudo o que eu puder, tudo o que for necessário, aqui me tem!". Mais adiante, afirmará para tranquilizar Luísa, diante do envolvimento desta com Basílio: - "Não há más mulheres, minha rica senhora, há maus homens, é o que há!" (1998, p. 274).

Os elogios dados a Sebastião arrefecem as ações tomadas pelo mesmo. No entanto, ele parece evidenciar uma realidade em que o narrador, com esmero, recalcara e escondera, para logo a seguir, desconstruí-la, revelando toda a dissimulação projetada. Em consequência, o que se vê, em última instância, é o comportamento do homem na sociedade burguesa europeia do século XIX, particularmente, uma pequena burguesia lisboeta - como resultado de relações construídas a partir das regras dessa sociedade. Nesse sentido, depara-se em $O$ primo Basílio a demonstração de uma tese de caráter social em que os indivíduos são, em grande parte, forjados sob a determinação de um meio hostil.

Em síntese, os sentimentos de bondade e de respeito, características predominantes na personagem Sebastião, tornam-se artificiais, caso sejam percebidos como componentes inerentes ao indivíduo. Somente quando confrontados em situações limites, pode-se afirmar o grau de responsabilidade ética do sujeito. Ainda assim, deparar-se-á com questões que dificilmente resolver-se-ão à luz da consciência individual. Talvez esteja aí a diferença central entre as atitudes de Basílio e Sebastião diante das oportunidades oferecidas pela beleza de Luísa. Enquanto o primo esquece-se do imperativo imposto por uma ética social das relações amorosas dominantes, satisfazendo-se plenamente com a prima, Sebastião assume inconscientemente sua adesão ao comportamento oficial da moral religiosa, desconsiderando seus desejos mais íntimos. A temeridade de Sebastião custa-lhe um duplo prejuízo afetivo: o afastamento de Jorge com o casamento e a morte de Luísa. Em Sebastião, o jeito silencioso de ser e o viver só, muito além de característica e opção, são marcas de uma existência em que o corpo, em momento algum, vivencia o prazer do seu desejo.

As limitações estruturais da personagem Sebastião protegem-na de uma interpretação mais extensa? Entende-se que a mesma constitui-se, naquele momento, uma promessa futura de riqueza temática a outras personagens que acabaram por se consolidar em termos de 
construção ${ }^{8}$. Todavia, em virtude da atualização do texto em contínuas recepções, valorizando a tese dos efeitos dos atos de leitura, já comentados, é possível encontrar, na figura da personagem Sebastião, ingredientes suficientes para uma abordagem renovada da categoria personagem, em particular, a secundária, readmitindo sua importância narrativa. Foi esta a intenção inicial da presente investigação.

\section{Referências}

ASSIS, Joaquim M. Machado de. Obras completas de Machado de Assis: Esaú e Jacó; críticas literárias; críticas teatrais. São Paulo: Formar, s/d.

BAKHTIN, Mikhail. Problemas da poética de Dostoiévski. Rio de Janeiro: Forense Universitária, 1997.

COELHO, Eduardo Prado. O reino flutuante. Lisboa: Edições 70, 1970.

CULLER, Jonathan. Sobre a desconstrução: teoria e crítica do pós-estruturalismo. Rio de Janeiro: Rosa dos Tempos, 1997.

CRUZ, Juliana Votto. Da sala de aula à prática docente: o ciclo de formação do professor e o ensino de literatura nas escolas da rede estadual em Rio Grande, RS. Tese (Doutorado) - Programa de Pós-Graduação em Letras, Instituto de Letras e Artes, Universidade Federal do Rio Grande, Rio Grande, 2016.
ECO, Umberto. Leitura do texto literário: Lector in fabula. Lisboa: Edições 70, 1979.

ECO, Umberto. Interpretação e superinterpretação. São Paulo: Martins Fontes, 1993.

FRAVOD, Charles-Henri. A psicanálise. Lisboa: Dom Quixote, 1976.

HAMON, Philippe. Por um estatuto semiológico da personagem. In: BARTHES, R. et al. Masculino, feminino, neutro: ensaios de semiótica narrativa. Porto Alegre: Globo, 1976.

ISER, Wolfgang. O ato de leitura. São Paulo: Editora 34, 1996.

MEZAN, Renato. O estranho caso de José Matias. In: NOVAES, Adauto (Org.). O desejo. São Paulo: Companhia das Letras, 1990.

QUEIRÓS, Eça. Cartas inéditas de Fradique Mendes e mais páginas esquecidas. Porto: Lello \& Irmãos, 1965.

QUEIRÓS, Eça. O primo Basílio. São Paulo: Ática, 1998.

REIS, Carlos; LOPES, Ana Cristina M. Dicionário de teoria da narrativa. São Paulo: Ática, 1988.

REIS, Carlos. Estatuto e perspectiva do narrador na ficção de Eça de Queirós. Coimbra: Almedina, 1975.

SARAIVA, António José e LOPES, Óscar. História da literatura portuguesa. Portugal: Porto, s/d.

Recebido: $16 / 11 / 16$

Aprovado: 21/01/17

Contato: jlgf@vetorial.net

\footnotetext{
8 Entre tantas personagens marcantes, se podem mencionar as de José Matias, Macário e Luísa Villaça que aparecem, respectivamente nos contos José Matias e As singularidades de uma rapariga loura.
} 